Бутаков П. А. Как верить преданно и твердо? // Философия. Журнал Высшей школы экономики. - 2020. - Т. 4, № 4. - С. 167-184.

\title{
ПАВЕЛ БУТАКОВ*
}

\section{КАК ВЕРИТЬ ПРЕААННО И ТВЕРАО?**}

Аннотация: Религиозные вероисповедные тексты подразумевают требование преданной и твердой веры в истинность изложенных в них догматов. Но как человек может достичь такой веры? Чтобы ответить на этот вопрос, в статье предлагается концептуальная схема для описания и классификации всех пропозициональных установок, обозначаемых словом «вера». Классификация строится на основе информации о том, является ли вера категорической или количественной, а также произвольной или непроизвольной. В рамках предложенной схемы все вероподобные установки разделяются на две группы, каждая из групп рассматривается как одна обобщенная пропозициональная установка. Обобщенная установка первой группы названа «мнением», а второй группы - «уверенностью». Мнение является категорической установкой, т. е. оно может иметь лишь одно из АВух истинностных значений - «истинно» и «ложно», а уверенность является количественной, т.е. может принимать любое значение от полной уверенности в ложности пропозиции до полной уверенности в ее истинности. При этом мнение произвольно, т.е. подчинено воле субъекта, а уверенность непроизвольна: она зависит от текущего содержания доксастической системы субъекта и напрямую не подчиняется его воле. Вдобавок предложен список факторов, влияющих на значение уверенности субъекта в истинности пропозиции: достоверность, желанность, этичность, центральность и укорененность пропозиции. На основании предложенной схемы сформулированы практические рекомендации для достижения того, что может быть названо «преданной и твердой верой» в некую пропозицию. Эти рекомендации включают как формирование мнения об истинности этой пропозиции, так и усиление уверенности в ее истинности. Предложенная схема и практические рекомендации обсуждаются на примере веры в истинность христианских догматов, однако все полученные результаты могут быть применены и за пределами религиозного контекста.

Ключевые слова: пропозициональные установки, степень веры, доксастический волюнтаризм, доксастический инволюнтаризм, вера, уверенность, доксастическая система.

DOI: $10.17323 / 2587-8719-2020-4-167-184$.

\section{1. ВВЕДЕНИЕ}

Цель данной статьи - дать ответ на вопрос о том, что нужно делать, чтобы иметь твердую веру в христианское вероучение. Согласно Афанасьевскому символу веры такая вера является необходимой для

*Бутаков Павел Анатольевич, к. филос. н., старший научный сотрудник, Институт философии и права CO PAH (Новосибирск), pavelbutakov@academ.org, ORCID: oooo-0oo1$8133^{-1626 .}$

** (C) Бутаков, П. А. (C) Философия. Журнал Высшей школы экономики. 
спасения. Этот символ представляет собой весьма пространный перечень тринитарных и христологических догматических утверждений католической церкви, а заканчивается он недвусмысленным вердиктом: «Это - католическая вера. Кто не будет верить в это преданно и твердо, тот не сможет спастись. Аминь». Что же делать человеку, который хочет выполнить требование Афанасьевского символа? Возможны ли здесь какие-то практические рекомендации по обретению такой веры?

Главным действующим лицом данной статьи будет Рекс-обычный мужчина средних лет, воспитанный в нецерковной среде, который вдруг по каким-то причинам захотел поверить в христианское учение. Имя Рекс навеяно персонажем романа Ивлина Во «Возвращение в Брайдсхед», где описывается трагикомичная история о том, как успешный бизнесмен и политик Рекс Моттрем ради выгодного брака пытается стать католиком. Он совершенно не разбирается в тонкостях католической теологии, благочестия и религиозных чувств. Его вопросы о том, что конкретно нужно сделать, чтобы стать католиком, вызывающе прямолинейны: какие документы подписать, какие слова говорить, кому и сколько заплатить. Его будущая теща, весьма религиозная традиционная католичка, пытается его образумить, говоря, что к Вере (именно так, с большой буквы) нужно относиться более серьезно и что негоже называться верующим, если в тебе нет искренней веры.

Подобно Рексу Моттрему наш Рекс готов обрести искреннюю веру, но не знает, что конкретно для этого нужно сделать. Он читает перечень догматов Афанасьевского символа и мысленно как бы соглашается с ними, но сомневается в том, является ли такое согласие той самой «преданной и твердой верой», без которой, как утверждается, невозможно спастись. Он был бы рад приложить усилия к тому, чтобы сделать свою веру более «преданной и твердой», но даже не представляет как. Поможем Рексу.

Статья будет состоять из двух частей. В первой части будет предложена единая концептуальная схема для описания разнообразных пропозициональных установок, которые могут быть названы словом «вера». Во второй части на основании этой схемы будут сделаны конкретные практические выводы о том, какие действия могут влиять на эту пропозициональную «веру».

\section{2. КАКИЕ БЫВАЮТ ВЕРЫ}

Слово «вера» имеет много значений. В одном только финальном вердикте Афанасьевского символа оно использовано три раза в трех 
разных смыслах: «Это-католическая вера. Кто не будет верить в это преданно (дословно: „верно“) и твердо...» ${ }^{1}$. Первая трудность, с которой сталкивается наш герой Рекс, - это разобраться с семантикой: что значит «верно верить в веру»?

С одним из этих трех значений Рексу разобраться нетрудно. Та «вера», в которую ему нужно поверить, - это просто набор пропозиций. В начале Афанасьевского символа сказано: «Вот это - католическая вера»после чего следует длинный список различных утверждений о триединстве Бога. Затем в середине символа вновь повторяется: «...вотправильная вера» - и далее приводится еще один перечень утверждений о богочеловечестве Иисуса Христа. И в конце подытоживается: «...это - католическая вера». Так что с объектом веры Рексу все ясно: от него требуется верить в сумму пропозиций, а точнее, в некую сложную пропозицию, образованную через конъюнкцию всех догматических утверждений Афанасьевского символа. Далее эту сложную пропозицию мы будем обозначать буквой $Q^{2}$. Афанасьевский символ не требует от Рекса ни веры в Бога, ни просто некой «Веры». Речь идет исключительно о пропозициональной вере. Рекс должен верить в $Q$ или, точнее, верить, что $Q$ истинно. Выражаясь более формально, Рекс должен верить, что $Q$.

Если с пониманием того, во что нужно верить, у Рекса проблем не возникает, то как именно в это $Q$ верить, совсем не ясно. Сказано, что надо не просто верить, а «верить верно (преданно)». А что, бывает какая-то неверная вера, или недостаточно верная, или вообще вера без веры? Как-то это все слишком неконкретно. Придется нам с Рексом обстоятельно разобраться с тем, что же такое эта «преданная и твердая вера». Далее мы для краткости будем называть ее $F F F^{3}$. Единственное, что мы пока что выяснили про $F F F$, - это пропозициональная установка, поскольку ее объектом является пропозиция $Q$. Можно так и говорить: Рекс должен иметь $F F F$, что $Q$. Но что еще кроме этого можно сказать про FFF?

${ }^{1} \mathrm{~B}$ латинском оригинале: «Haec est fides catholica, quam nisi quisque fideliter firmiterque crediderit, salvus esse non poterit»-где credo (верю) - это глагол, функционирующий в качестве глагольной формы существительного fides (вера).

${ }^{2}$ Афанасьевский символ чаще называют по его первым словам-Quiqunque vult, поэтому обозначение его пропозиционального содержания буквой $Q$ наиболее уместно.

${ }^{3}$ FFF- это аббревиатура латинских слов из Афанасьевского символа: fides (вера), fideliter (верно, преданно) и firmiter (твердо). 
Эпистемологи выделяют целый ряд разных пропозициональных установок, которые можно обозначить словом «вера» или как-то уподобить вере. Их принято называть «вероподобными установками» или belief-like attitudes (далее просто $B L A$ ). K ним, например, относятся согласие, убежденность, мнение, суждение, принятие, предположение, уверенность и т. п. С легкой руки Дэвида Юма все это разнообразие сегодня принято обобщать в некую единую пропозициональную установку «веру»(belief) ${ }^{4}$. Юмовская вера-это связывание пропозиции с истинностным значением. Здесь важен не столько процесс, сколько результат: в конце концов, в сознании человека некая пропозиция оказывается либо истинной, либо ложной.

Казалось бы, здесь наш Рекс должен успокоиться, ведь он точно не считает Афанасьевский символ ложным. Выходит, что он мысленно приписал пропозиции $Q$ значение «истинна», и, согласно юмовской эпистемологии, у него уже есть «вера, что $Q »$, и этого должно быть достаточно. Как ни печально, Юм не признал бы такое мысленное согласие Рекса за настоящую веру. В юмовской эпистемологии вераэто результат накопленного опыта и знаний. Она основывается на имеющемся фактическом подтверждении, а не на наших прихотях. Человек не может просто взять, захотеть и поверить во что-то. Поэтому даже если Рекс твердо решит поверить в $Q$, то он все равно не сможет этого сделать до тех пор, пока у него не будет достаточного подтверждения истинности $Q$.

Рекс растерян. Согласно Юму, он никогда не сможет поверить в $Q$, ведь ему никогда не найти достаточного фактического подтверждения христианской догмы. Тем не менее Афанасьевский символ предъявляет требование верить в $Q$, тем самым как бы подразумевая, что это в принципе достижимо. В конце концов, ведь есть же какие-то святые, которые верят и спасаются. Неужели у них есть доступ к каким-то секретным фактам, недоступным остальным людям? Вряд ли. Рекс приходит к выводу, что, скорее всего, авторы Афанасьевского символа не были последователями юмовской эпистемологии и их $F F F$ - это не юмовская вера, а какая-то другая $B L A$. Ведь $F F F$ - это не простая вера, а как минимум «преданная и твердая», что уже выходит за рамки стандартной юмовской картины.

4Д. Юм, Трактат о человеческой природе I.III.7-9. Об инфляции термина belief см.: Alston, 1996: 20. 
Пытаясь понять, чем вообще может быть $F F F$, Рекс видит два возможных варианта. Первый вариант: $F F F$ - это все-таки более-менее стандартная (обобщенная, неспецифическая) $B L A$, обыденная вера, только каким-то образом модифицированная, усиленная до состояния «преданности и твердости». В этом случае отличительным свойством $F F F$ будет количественная характеристика. Второй вариант: $F F F-$ это какая-то специфическая $B L A$. Другими словами, рассматриваемая «преданная и твердая вера»-это какой-то особый вид веры, отличающийся от других качественно, а не количественно. В первом варианте Рексу нужно понять, какими способами можно усиливать уже имеющуюся у него «BLA, что $Q \gg$. И если он приложит достаточно усилий, то его $\langle B L A$, что $Q »$ сама автоматически превратится в желанную $« F F F$, что $Q \gg$. Во втором варианте Рексу ничего не нужно усиливать. Зато ему придется как-то сразу (с нуля) обрести $« F F F$, что $Q \gg$ в готовом виде.

Рекс совсем запутался. Теперь перед ним уже не один, а два выбора. Первый выбор-между той верой, которая не зависит от наших решений и подчиняется лишь фактическим подтверждениям, и той, которой всетаки можно управлять по своему желанию. Второй выбор-искать ли Рексу какого-то особого вид веры, которого у него пока нет, или же надо работать над усилением и укреплением обычной веры, которая у него уже есть.

Оказывается, что Рекс не одинок в своих терзаниях. Та же самая неопределенность присутствует не только в религиозном контексте, но и в обыденном и даже научном познании. Современные эпистемологи ведут жаркие споры о природе веры, среди которых обсуждаются те же самые проблемы, с которыми столкнулся Рекс. Во-первых, о том, можем ли мы контролировать наши верования, и, во-вторых, о том, имеют ли наши верования степень интенсивности. Тех, кто считает, что наша пропозициональная вера неподвластна нашей воле, называют доксастическими инволюнтаристами 5 . Соответственно, доксастические волюнтаристы - это те, кто считает иначе, т. е. что мы по своей воле можем управлять тем, в какие пропозиции мы верим ${ }^{6}$. Во-вторых,

5 Речь идет о невозможности непосредственного волевого контроля над верованиями; при этом инволюнаристы вовсе не отрицают возможности целенаправленного опосредованного воздействия на собственную веру. Инволюнтаристская позиция стала доминировать в эпистемологии в конце XX века (см., напр.: Alston, 1996: 7-8). Чаще всего инволюнтаризм оказывается связан с позицией эвиденциализма (см.: Conee \& Feldman, 2004).

${ }^{6}$ Одним из главных доводов в пользу волюнтаризма является этика веры, которая возлагает на человека ответственность за его верования и тем самым подразумевает 
есть те, кто считает, что пропозициональная вера-это категорическая установка, т.е. что она не имеет степени: мы верим либо что некая пропозиция истинна, либо что она ложна (некоторые зачем-то добавляют сюда еще и третье промежуточное значение - «воздержание от суждения»)7. А их противники полагают, что пропозициональная вераэто количественная установка, которая имеет варьирующуюся от о до 1 степень интенсивности, где о-это состояние полной уверенности в ложности пропозиции, 0.5- состояние воздержания от суждения, а 1 состояние полной уверенности в истинности пропозиции ${ }^{8}$.

Так кто же из них прав? Волюнтаристы или инволюнаристы, «категоричники» или «количественники»9? Какой из четырех вариантов следует выбрать Рексу? Он понимает, что на кону его спасение и вечная жизнь, поэтому неверный выбор будет иметь весьма печальные последствия. Мы посоветуем Рексу как человеку практичному не пренебрегать ни одним из вариантов. Лучше перестраховаться и выбрать сразу все. Далее я изложу схему, в рамках которой я постараюсь объединить и примирить все четыре вышеизложенные точки зрения ${ }^{10}$.

В основе предлагаемой схемы лежат две весьма спорных гипотезы, которые я продекларирую, но не буду обосновывать.

наличие у него свободы формирования верований. См.: Mourad, 2008; Wood, 2008; Steup, 2017.

7 В качестве наиболее яркого примера защиты категорической природы веры можно привести недавние работы Эндрю Муна: Moon, 2017; Moon, Jackson, 2020.

${ }^{8} \mathrm{~B}$ современной эпистемологии количественный подход к оценке веры является более популярным. Помимо этого, он применяется в формальной эпистемологии, в теории игр, в теории принятия решений и в др., где степень веры соотносится с субъективной оценкой вероятности истинности пропозиции и подсчетом риска. См., напр.: Eriksson, Hájek, 2007; Schwitzgebel, 2015: 2.4.

${ }^{9}$ Мне неизвестно, существует ли на сегодняшний день общепризнанное название сторонников этих двух лагерей, которых я назвал «категоричниками» и «количественниками». Больше всех мне нравится вариант, соответственно, «belief-first» и «credence-first» (cм.: Moon, Jackson, 2020: 653). Традиционно в рамках данной полемики слово belief зарезервировано за теми, кто считает, что вера не имеет степени. А ту веру, которая имеет степень, называют credence. Сторонники «belief-first» считают, что установка beliefбазовая, a credence - ее разновидность - вера, что вероятность истинности пропозиции имеет такое-то численное значение. Сторонники «credence-first» считают базовой credence, a belief рассматривают как ту разновидность credence, значение которой равно 1 или близко к 1. Необходимо также отметить, что подавляющее большинство как «категоричников», так и «количественников» являются при этом инволюнтаристами. Насколько мне известно, в рамках волюнтаризма спор о том, является ли вера категорической или количественной, не ведется.

${ }^{10}$ Предлагаемая здесь схема была уже использована мною ранее в работе: Бутаков, 2019 . 
(1) Среди множества всевозможных $B L A$ какие-то $B L A$ являются произвольными (т. е. подвластными нашей воле), а какие-то непроизвольными; какие-то $B L A$ являются категорическими (т. е. не имеют степени), а какие-то количественными.

(2) Множество произвольных $B L A$ совпадает с множеством категорических $B L A$, а множество непроизвольных $B L A$ совпадает с множеством количественных $B L A$.

Особенно спорной является вторая гипотеза. При этом обе гипотезы мне самому кажутся интуитивно верными. Я пришел к ним в результате рефлексии над происходящими во мне когнитивными процессами и, конечно же, вполне допускаю как возможность ошибки, так и возможность того, что когнитивные процессы у других людей протекают как-то иначе. Тем не менее, основанная на этих гипотезах схема представляется мне простой и эффективной и при этом не менее правдоподобной, чем другие известные мне схемы. Вдобавок она способна примирить противоположные эпистемологические концепции, коль скоро в рамках этой схемы все четыре вышеуказанных точки зрения оказываются верными, просто их объектами являются разные $B L A$.

Итак, я предлагаю разделить все $B L A$ на две группы в соответствии с гипотезой (2). В первой группе окажутся те $B L A$, которые могут иметь только два значения - истинное и ложное, - и человек вполне может сам решать, какое из этих значений им приписывать. Например, в этой группе будут такие $B L A$, как «придерживаться мнения», «выносить суждение», «считать», «принимать решение», «делать предположение» и т. п. Во вторую группу попадут те $B L A$, которые могут иметь различные степени интенсивности, и люди не способны по своей воле управлять тем, какова эта степень. Здесь окажутся такие установки, как «быть уверенным», «склоняться», «быть согласным», «быть убежденным», и, наконец, «верить» в обыденном значении этого слова ${ }^{11}$.

Но на этом схема пока не заканчивается. Следующий шаг: мы не будем дифференцировать $B L A$ внутри каждой из двух групп и, следовательно, сведем все лингвистическое и ментальное разнообразие всевозможных видов пропозициональных вер лишь к двум пропозициональным установкам. То есть все те $B L A$, которые оказались в первой группе, мы будем рассматривать как некую единую установку, скажем, $B L A_{1}$, а те,

${ }^{11} Я$ должен признать, что мои лингвистические интуиции несовершенны, и поэтому я допускаю, что какие-то установки из этих двух групп, возможно, следует либо удалить, либо даже переместить в другую группу. 
которые попали во вторую группу, - как $B L A_{2}$. Получается, что есть только две вероподобных пропозициональных установки: $B L A_{1}$ и $B L A_{2}$. Первая является категорической и произвольной, а вторая - количественной и непроизвольной. Первая охватывает все те случаи, когда мы делаем осознанный однозначный выбор между «да» и «нет». Вторая отражает то, насколько сильно мы на самом деле испытываем внутреннюю уверенность в истинности того или иного высказывания.

Чтобы завершить схему, нам нужно избавиться от технических аббревиатур и перейти на человеческий язык. Для этого необходимо как-то переименовать $B L A_{1}$ и $B L A_{2}$, подыскав им наиболее подходящие аналоги в русском языке. На эти роли я предлагаю слова «мнение» и «уверенность». Итак:

Мнение - это такая вероподобная пропозициональная установка, которая может иметь лишь одно из двух значений - «истинно» либо «ложно»и которая непосредственно формируется субъектом по его воле.

Уверенность - это такая вероподобная пропозициональная установка, которая может иметь любое значение в интервале между несомненной истинностью и несомненной ложностью и которая не зависит напрямую от воли субъекта ${ }^{12}$.

Мнение - это то, что напрямую связано с нашими решениями. Мы формируем мнение всякий раз, когда нам необходимо основание для действия: когда нужно сделать публичное заявление, когда нужно выбрать посылки для построения аргумента или когда нужно принять практическое решение. При этом сформированное мнение далеко не всегда соответствует тому, насколько мы на самом деле в этом уверены. А вот уверенность как раз отражает наше подлинное внутреннее ментальное состояние $^{13}$. В истинности каких-то пропозиций мы уверены сильнее, а в истинности других - слабее. При этом мы не можем вдруг взять и напрямую изменить эту внутреннюю степень уверенности, стать более

${ }^{12}$ Я должен вновь сослаться на несовершенство моих лингвистические интуиций. Если кому-то слова «мнение» и «уверенность» покажутся неподходящими кандидатами для обозначения $B L A_{1}$ и $B L A_{2}$, то я призываю обращать внимание не столько на сами слова, сколько на приведенные определения.

133десь стоит уточнить, что сам факт наличия у человека некой уверенности с определенным значением еще не означает, что человек осознает величину своей уверенности и может сходу назвать соответствующее число. Но это также не означает, что человек не может оценить свою уверенность. Никакой связи между наличием уверенности и способностью ее оценить нет. 
(или менее) уверенными в чем-либо. Однако со временем наша уверенность может измениться благодаря новым знаниям, приобретенному опыту и, по-видимому, еще целому ряду других факторов.

Вот, собственно, и вся схема. Она сводится к тому, что каждая пропозициональная вера является либо мнением, либо уверенностью. Что это нам дает? Главным для нас следствием этой схемы является то, что мы, зная какое-то одно свойство пропозициональной веры, можем определить ее другие свойство. Например, если мы знаем, что вера непроизвольная, то это значит, что речь идет об уверенности, и, следовательно, эта вера должна быть количественной. А если вера произвольная, значит, это-мнение, которое всегда категорическое. Если вся вера упирается в простой выбор между «да» или «нет», между «за»или «против», то для обретения такой веры достаточно волевым усилием принять соответствующее решение. Если же какая-то вера подразумевает степень внутренней убежденности, то это означает, что она непроизвольная и нам в лучшем случае придется довольствоваться лишь косвенным контролем над ней.

Поскольку мы с Рексом сразу же установили, что $F F F$ - это пропозициональная вера, то теперь, следуя принятой схеме, мы можем утверждать, что $F F F$ - это либо мнение, либо уверенность. Возможно даже, что $F F F$ - это собирательный термин, который как-то объединяет и мнение, и уверенность. Рекс не знает, что такое $F F F$, но он непременно хочет обрести $« F F F$, что $Q \gg$. Чтобы не прогадать, Рексу придется работать сразу в обоих направлениях: ему нужно и формировать «мнение, что $Q »$, и усиливать «уверенность, что $Q \gg$. Какие конкретные действия ему следует предпринять?

\section{3. КАК ОБРЕСТИ ВЕРУ}

В рамках представленной схемы мнение и уверенность являются разными и не связанными друг с другом пропозициональными установками, поэтому и рассматривать их следует отдельно. Далее будут представлены два независимых раздела: один - простой и короткийпро мнение, а другой - про уверенность.

3.1. Как сформировать мнение. Как уже было сказано, мнение - это то, что непосредственно связано с действием и принятием решений. Мнение высказывают, его отстаивают в спорах, ему следуют при совершении практических действий. В каждой из этих трех областей - речи, мышлении и практике- мнения играют ключевую роль. То, что мы произносим, как мы рассуждаем и как мы поступаем, состоит из мнений 
или напрямую вытекает из них. Иногда эти мнения бывают взвешенными, отрефлексированными, а иногда - спонтанными, необдуманными. Иногда мы отстаиваем свою собственную точку зрения и поступаем так, как свойственно нам, а иногда в силу разных причин мы беремся защищать чужую позицию или соучаствуем в каких-то несвойственных нам действиях. Наши мнения полностью подчинены нашей воле, и мы способны говорить, рассуждать и поступать так, как хотим.

Рекс- как человек практичный - здесь может облегченно вздохнуть. Если $F F F$ - это мнение, то совсем нетрудно понять, как иметь $« F F F$, что $Q \gg$. Грубо говоря, надо всего лишь говорить, рассуждать и поступать в согласии с $Q$. Например, если Рекса спросят, есть ли Бог, то ему следует отвечать в соответствии с $Q$, что Бог есть. Если Рекс вдруг задумается о том, способен ли Бог сопереживать нам в наших страданиях, то ему следует приобщить к своим размышлениям посылки, взятые из $Q$, где, в частности, сказано, что Иисус Христос-Бог и что Иисус Христос пострадал за нас. А если Рексу предстоит выбор между добрым и злым поступком, то ему следует не забывать о той части $Q$, где сказано, что делавшие добро пойдут в жизнь вечную, а делавшие зло - в вечный огонь.

Здесь кто-то может возмутиться: это не похоже на искреннюю веpy, a, скорее, напоминает притворство. Все эти рекомендации - лишь внешняя оболочка, а как же внутреннее содержание? На это можно привести ряд возражений. Во-первых, я вовсе не утверждаю, что «FFF, что $Q \gg$ сводится лишь к правильным словам, посылкам и поступкам.

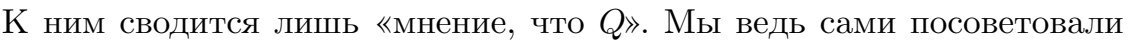
Рексу учитывать не только «мнение, что $Q »$, но и «уверенность, что $Q »$, о которой речь пойдет в следующем разделе. Во-вторых, раз уж речь идет о христианстве, то в подтверждение этой концепции можно привести некоторые новозаветные высказывания ${ }^{14}$. В-третьих, требование иметь «мнение, что $Q \gg$ хоть и легко понять, но не так-то легко выполнить. Устное произнесение $Q$ может закончиться мученической смертью. Попытка рационального осмысления всех тринитарных и христологических положений $Q$ приводит к парадоксам и логическим противоречиям христианской теологии. А практические действия в соответствии с $Q$

${ }^{14}$ Например, про устное исповедание: «[Христос сказал:] всякого, кто исповедает Меня пред людьми, того исповедаю и Я пред Отцом Моим Небесным; а кто отречется от Меня пред людьми, отрекусь от того и Я пред Отцом Моим Небесным» (Мф. 10: $3^{2-} 33$ ). Про веру, состоящую из правильных поступков: «Покажи мне веру твою без дел твоих, а я покажу тебе веру мою из дел моих» (Иак. 2:18). 
иногда требуют того, что принято называть «прыжком веры», когда весь накопленный жизненный опыт, знания и здравый смысл вступают в конфликт с поступком, основанным на $Q$.

Итак, с «мнением, что $Q \gg$ Рексу все ясно: чтобы спастись, нужно говорить, рассуждать и поступать так, чтобы это согласовывалось с $Q$. Но как управлять неуправляемой «уверенностью, что $Q » ?$

3.2. Как укрепить уверенность. Прежде чем перейти к обсуждению уверенности, сначала нужно обратиться к понятию доксастической системы ${ }^{15}$. Я буду называть доксастической системой множество всех содержащихся в сознании субъекта пропозиций и взаимосвязей между ними ${ }^{16}$. Анализ взаимосвязей между пропозициями доксастической системы позволяет субъекту определить свое отношение к достоверности этих пропозиций, т. е. определить свои пропозициональные установки ${ }^{17}$.

Каким образом пропозициональные установки определяются доксастической системой? Поясню на упрощенном примере. Элементом доксастической системы Рекса является пропозиция «Лондон - столица Великобритании». Допустим, Рексу нужно определиться со своим отношением к этой пропозиции. Он находит в своей доксастической системе другие пропозиции, которые связаны с ней: «Мои знакомые считают Лондон столицей Великобритании», «В книгах, фильмах и СМИ Лондон называют столицей Великобритании», «Я сам, бывая в Лондоне, видел подтверждения того, что это - столичный город». Вдобавок у Рекса есть еще один дополнительный набор нормативных пропозиций: «Я вполне доверяю данным своего эмпирического опыта», «Я считаю правильным следовать мнению большинства» и «Мне приятно иметь те же взгляды, что и у моих друзей». На основании всех этих пропозиций Рекс приходит к выводу: он полностью уверен в том, что пропозиция «Лондон - столица Великобритании» истинна.

Этот пример, несмотря на его простоту, показывает, что сила уверенности субъекта в истинности какой-то конкретной пропозиции определяется множеством параметров: другими пропозициями и силой уверен-

${ }^{15}$ В диахроническом контексте доксастическая система может называться «эпистемической ситуацией».

${ }^{16}$ Обычно доксастическую систему определяют как множество всех пропозициональных установок субъекта. Нам это определение не подходит, поскольку перед нами стоит обратная задача: определить пропозициональную установку - уверенность - через доксастическую систему.

${ }^{17}$ При этом для нас не принципиально, насколько осознанным и отрефлексированным является производимый субъектом анализ. См. также сн. 13. 
ности в них, а также методологическими, этическими, эмоциональными и иными предпочтениями, то есть уверенность в истинности пропозиции зависит от целого ряда факторов. Это означает, что даже если субъект не способен воздействовать на свою уверенность напрямую, он может воздействовать на нее косвенно посредством изменения влияющих на нее факторов. Далее я перечислю наиболее значимые из них.

Достоверность. Этим словом я буду называть силу имеющегося фактического подтверждения пропозиции, т.е. того, что в современном английском языке принято называть словом evidence. Чем сильнее подтверждение, тем выше достоверность пропозиции. В сознании Рекса пропозиция «Лондон - столица Великобритании»имеет высокую степень достоверности, а пропозиция $Q$ - низкую. Достоверность является решающим фактором при определении степени уверенности. Однако это не единственный фактор.

Желанность. Иногда люди уверены в чем-то не потому, что это имеет высокую степень достоверности, а потому, что им просто этого очень хочется. Например, Рекс полностью уверен в том, что его жена ему не изменяет. У него нет никаких фактических подтверждений отсутствия измены (да и какие они могут быть?), и его уверенность преимущественно основана на желании того, чтобы это было правдой. Здесь же стоит упомянуть и следующий факт: зачастую люди верят в некую идею лишь потому, что она им нравится, или для них весьма желанны ее следствия, или им нравится конкретный человек, высказавший ее.

Этичность. Иногда люди сильнее верят в то, во что верить хорошо и правильно, и затрудняются верить в то, что считают неправильным. Например, Рекс очень слабо верит эмпирическим данным Джеймса Уотсона об интеллектуальном превосходстве белых над чернокожими именно потому, что считает любые расистские идеи злом.

Центральность. Одни пропозиции занимают центральное положение в доксастической системе, а другие - периферийное. Центральность пропозиции проявляется в том, насколько часто она задействуется в повседневной жизни, поведении и мышлении. Чем чаще человек полагается на истинность пропозиции, тем она центральнее, а чем она центральнее, тем проще человеку быть уверенным в ее истинности. Например, Рекс привык в своем повседневном общении исходить из того, что окружающие его люди рациональные и добрые, и вследствие этого он вполне уверен в том, что люди рациональны и добры. 
Укорененностъ. Некоторые пропозиции прочно укоренены внутри доксастической системы. Они тесно связаны с множеством других пропозиций, и отношение к ним не может измениться без того, чтобы не затронуть всю остальную систему. Слабо укорененные пропозиции не имеют прочных связей с остальной системой, и отношение к ним может измениться легко и безболезненно. Например, Рекс глубоко убежден, что может всецело доверять своим чувственным ощущениям, и было бы очень сложно уверить его в обратном, не нанеся при этом непоправимого урона всей его доксастической системе ${ }^{18}$.

Список перечисленных факторов, возможно, не полный. Тем не менее я считаю, что самые важные факторы здесь упомянуты. Суммарная уверенность человека в истинности пропозиции складывается из всех этих факторов, причем разные факторы имеют разный вес. Наиболее значимый фактор-это достоверность пропозиции, далее идет группа менее важных факторов: личные приоритеты (желанность, этичность) и место внутри системы (центральность, укорененность). По-видимому, удельный весь каждого из факторов неодинаков для всех людей и всех ситуаций. Кто-то больше полагается на эмпирику, а кто-то-на этику. Иногда мы больше доверяем уму, а иногда-сердцу. В любом случае увеличение любого из этих факторов все равно будет в целом способствовать росту уверенности.

Итак, перед Рексом стоит задача - достичь высокой степени «уверенности, что $Q \gg$. Сейчас Рекс чувствует, что его «уверенность, что $Q »$, весьма невелика и он не знает, как это изменить. Попробуем вместе с Рексом проанализировать его текущую уверенность, рассмотрев влияющие на нее факторы. Начнем с достоверности: ясно, что у Рекса нет веских фактических подтверждений $Q$. А желанность? Насколько сильно Рекс хочет, чтобы $Q$ было истиной? Если честно, то не очень. Может быть, Рекс считает веру в христианскую догму высоконравственной? Но и тут он обнаруживает в себе конфликтующие тенденции. Наконец, занимает ли христианское вероучение центральное место в его мышлении и насколько сильно оно укоренено в нем? Вообще никак.

Если наш Рекс все-таки намерен во что бы то ни стало начать наращивать свою уверенность, то ему следует начать работать над усилением каждого из упомянутых факторов.

${ }^{18}$ Я заимствую факторы центральности и укорененности из работ Роберта Ауди: Audi, 2008: 89 . 
Как повысить степень достоверности? Поскольку достоверность напрямую зависит от имеющегося подтверждения, то Рексу просто нужно начать искать и накапливать подтверждения $Q$. Здесь на ум приходят, с одной стороны, эмпирические подтверждения, например, исторические свидетельства, подтверждающие евангельскую историю, а с другой стороны, теоретические подтверждения: философские аргументы в пользу существования Бога и рациональная интерпретация тринитарного и христологического догматов ${ }^{19}$.

Как Рексу увеличить желанность $Q$, т. е. сильнее этого хотеть? Боюсь, что здесь я не могу предложить ничего конкретного. Возможно, тут могло бы помочь знакомство с какими-нибудь замечательными людьми, исповедующими $Q$, благодаря чему у Рекса появилось бы желание стать таким же, как они. Но вряд ли нам стоит рекомендовать Рексу заняться целенаправленным поиском таких людей.

Можно ли как-то поработать над этичностъю веры в $Q$ ? Я полагаю, что для этого Рексу стоит поменьше заострять внимание на тех злодеяниях, которые совершаются во имя христианской веры, и разузнать побольше о том, что хорошего сделали христиане.

А как повысить степень центральности и укорененности $Q$ в доксастической системе Рекса? Здесь ответ достаточно очевиден: чтобы быть центральной, пропозиция должна быть постоянно активно задействована. Если Рекс плотно займется изучением теологии, общением с другими верующими, начнет посещать богослужения и приобщаться к христианской церковной жизни, то $Q$ автоматически переместится с периферии сознания Рекса в его центр. Заодно $Q$ со временем обрастет сетью дополнительных связей с другими пропозициями, что увеличит степень укорененности $Q$ в сознании Рекса.

Возможно, есть и другие факторы, и другие рецепты, способствующие росту «уверенности, что $Q$ ». Но нам нет необходимости составлять исчерпывающий список, так как общая стратегия в целом уже ясна. Напоследок хочется предложить Рексу еще один ранее не упоминавшийся способ увеличения уверенности. Многие христиане считают, что вера - это сверхъестественный дар, который можно получить через принятие церковных таинств. Так что Рекс вполне может попробовать и этот способ.

${ }^{19}$ Кэтрин Дорманди утверждает, что поиск подтверждений является вполне естественным следствием религиозной веры: Dormandy, 2018. 


\section{4. ЗАКЛЮЧЕНИЕ}

Итогом статьи является концептуальная схема, в рамках которой все вероподобные пропозициональные установки разделяются на две группы и каждая из групп рассматривается как одна обобщенная пропозициональная установка. Обобщенная установка первой группы названа мнением, а обобщенная установка второй-уверенностью. Мнение характеризуется тем, что может иметь лишь одно из двух истинностных значений - «истинно» и «ложно», - а уверенность может принимать любое значение от полной уверенности в ложности пропозиции до полной уверенности в ее истинности. При этом мнение подчинено воле субъекта, а уверенность зависит от текущего содержания доксастической системы субъекта и напрямую не подчиняется его воле. Вдобавок предложен список факторов, влияющих на значение уверенности субъекта в истинности пропозиции: достоверность, желанность, этичность, центральность и укорененность. На основании предложенной схемы сформулированы практические рекомендации для достижения того, что может быть названо «преданной и твердой верой» в некую пропозицию. Эти рекомендации включают как формирование мнения об истинности этой пропозиции, так и усиление уверенности в ее истинности.

Несмотря на то что проблема обретения «преданной и твердой веры» здесь сформулирована в контексте религиозной веры в христианское вероучение, в статье нет специфических религиозных или теологических аргументов. Все результаты и рекомендации статьи могут быть одинаково применены к любой пропозициональной вере- обыденной или даже научной. Однако стоит еще раз подчеркнуть, что все представленные рассуждения применимы лишь к пропозициональной вере, т. е. «вере, что ...», и никак не касаются других видов веры: «веры в кого-то», «веры во что-то» или просто «Веры».

В первую очередь статья написана для тех людей, которые заявляют, что они, дескать, хотели бы поверить, но не могут. Я надеюсь, что приведенные рекомендации могут помочь тем, кто действительно хочет поверить. Для тех же, кто использует свою «неспособность поверить» лишь в качестве формального извинения, эти рекомендации послужат веским возражением: «Если хочешь верить-делай так, а если не делаешь - значит на самом деле не хочешь».

Я надеюсь, что, помимо практической пользы, результаты статьи имеют и чисто научную, философскую ценность, так как в ней предложена 
промежуточная, примирительная концепция для, во-первых, соперничающих эпистемологических теорий доксастического волюнтаризма и инволюнтаризма, и, во-вторых, спора о том, имеет ли пропозициональная вера степень интенсивности. Наконец, она вносит свой вклад в попытки философов навести порядок во всем многообразии лингвистических выражений и ментальных установок, связанных с верой ${ }^{20}$.

\section{ЛИТЕРАТУРA}

Бутаков П. А. Почему эвиденциалисты должны верить обещаниям // Философия : Журнал Высшей школы экономики. - 2019. - Т. 3, № 3. - С. 172-200. Alston W. P. Belief, Acceptance, and Religious Faith // Faith, Freedom, and Rationality : Philosophy of Religion Today / ed. by J. Jordan, D. Howard-Snyder. Lanham : Rowman \& Littlefield, 1996. - P. $3^{-27}$.

Audi R. Belief, Faith, and Acceptance // Ethics of Belief : Essays in Tribute to D. Z. Phillips / ed. by E. T. Long, P. Horn. - Dordrecht : Springer, 2008. - P. 87-102.

Conee E., Feldman R. Evidentialism : Essays in Epistemology. - Oxford : Clarendon Press, 2004.

Dormandy K. Evidence-Seeking as an Expression of Faith // American Catholic Philosophical Quarterly. - 2018. - Vol. 92. - P. 409-428.

Eriksson L., Hájek A. What are Degrees of Belief? // Studia Logica. - 2007. Vol. 86, no. 2. - P. $183^{-213}$.

Moon A. Beliefs Do Not Come in Degrees // Canadian Journal of Philosophy. 2017. - Vol. 47, no. 6. - P. 1-19.

Moon A., Jackson E. Credence : A Belief-First Approach // Canadian Journal of Philosophy. - 2020. - Vol. 50, no. 5. - P. 652-669.

Mourad R. Choosing to Believe // International Journal for Philosophy of Religion. 2008. - Vol. 63. - P. 55-69.

Schwitzgebel E. Belief / The Stanford Encyclopedia of Philosophy ; ed. by E. N. Zalta. - 2015. - URL: https://plato.stanford.edu/archives/sum2015/entries/ belief (visited on Dec. 14, 2018).

Steup M. Believing Intentionally // Synthese. - 2017. - Vol. 194, no. 8. - P. 26732694 .

Wood A. The Duty to Believe According to the Evidence // Ethics of Belief : Essays in Tribute to D. Z. Phillips / ed. by E. T. Long, P. Horn. - Dordrecht : Springer, 2008. - P. $7^{-24}$.

${ }^{20}$ Я благодарен участникам семинара «Знание и его границы: о чем следует молчать?», проходившем 17-18.09.2019 на базе НИУ ВШЭ и ИФ РАН (Москва) и особенно Виктору Горбатову за ценные идеи, высказанные относительно предыдущей версии данной работы. 
Butakov, P. A. 2020. "Kak verit' predanno i tverdo? [How to Believe Faithfully and Firmly?]" [in Russian]. Filosofiya. Zhurnal Vysshey shkoly ekonomiki [Philosophy. Journal of the Higher School of Economics] 4 (4), 167-184.

\author{
Pavel Butakov \\ PhD in Philosophy, Senior Research Fellow \\ Institute of Philosophy and LAW OF the SB RAS (Novosibirsk, RUsSia); \\ ORCID: 0000-0001-8133-1626
}

\title{
How to Believe FAITHFulLy AND FiRMLY?
}

\begin{abstract}
Religious people are expected to believe in their religious creeds faithfully and firmly. How can one acquire such belief? In order to answer that question, I propose a model for all belief-like propositional attitudes. The model differentiates, firstly, between voluntary and involuntary, and, secondly, between categorical and quantitative belief-like attitudes. The whole variety of belief-like attitudes is then reduced into two main groups. The first group combines all voluntary and categorical attitudes, and the second group combines all involuntary and quantitative attitudes. The resultant first-group attitude is called "judgment," and the second-group attitude - "confidence." Thus, judgment is the generic voluntary categorical propositional attitude, which can have only two values: "true" or "false." Confidence is the generic involuntary quantitative attitude, which can have any value between "certainly false" and "certainly true." A religious person can form the creedal judgment simply by her act of will, while her confidence depends upon the actual content of her doxastic system. However, a person can indirectly increase her confidence in the creedal statement via relevant factors that control her doxastic system. Such factors include corroboration, desirability, and ethicality of the proposition, and also its centrality and entrenchment in the doxastic system. I suggest several practical guidelines for increasing the relevant factors. I claim that the suggested model and the practical guidelines for acquiring the "faithful and firm belief" can be used not only within the religious context, but can also be applied to any propositional beliefs.
\end{abstract}

Keywords: Propositional Attitudes, Degrees of Belief, Doxastic Voluntarism, Doxastic Involuntarism, Belief, Credence, Doxastic System.

DOI: $10.17323 / 2587-8719-2020-4-167-184$.

\section{REFERENCES}

Alston, W.P. 1996. "Belief, Acceptance, and Religious Faith." In Faith, Freedom, and Rationality : Philosophy of Religion Today, ed. by J. Jordan and D. Howard-Snyder, 3-27. Lanham: Rowman \& Littlefield.

Audi, R. 2008. "Belief, Faith, and Acceptance." In Long and Horn 2008, 87-102.

Butakov, P. A. 2019. "Pochemu evidentsialisty dolzhny verit' obeshchaniyam [Why Evidentialists Must Believe in Promises]" [in Russian]. Filosofiya [Philisophy]: Zhurnal Vysshey shkoly ekonomiki [Journal of the Higher School of Economics] 3 (3): 172-200.

Conee, E., and R. Feldman. 2004. Evidentialism: Essays in Epistemology. Oxford: Clarendon Press.

Dormandy, K. 2018. "Evidence-Seeking as an Expression of Faith." American Catholic Philosophical Quarterly 92:409-428.

Eriksson, L., and A. Hájek. 2007. "What are Degrees of Belief?" Studia Logica 86 (2): 183-213. Moon, A. 2017. "Beliefs Do Not Come in Degrees." Canadian Journal of Philosophy 47 (6): $1-19$. 
Moon, A., and E. Jackson. 2020. "Credence: A Belief-First Approach." Canadian Journal of Philosophy 50 (5): 652-669.

Mourad, R. 2008. "Choosing to Believe." International Journal for Philosophy of Religion 63:55-69.

Schwitzgebel, E. 2015. "Belief." The Stanford Encyclopedia of Philosophy. Accessed Dec. 14, 2018. https://plato.stanford.edu/archives/sum2015/entries/belief.

Steup, M. 2017. "Believing Intentionally." Synthese 194 (8): 2673-2694.

Wood, A. 2008. "The Duty to Believe According to the Evidence." In Long and Horn 2008, $7^{-24}$. 